
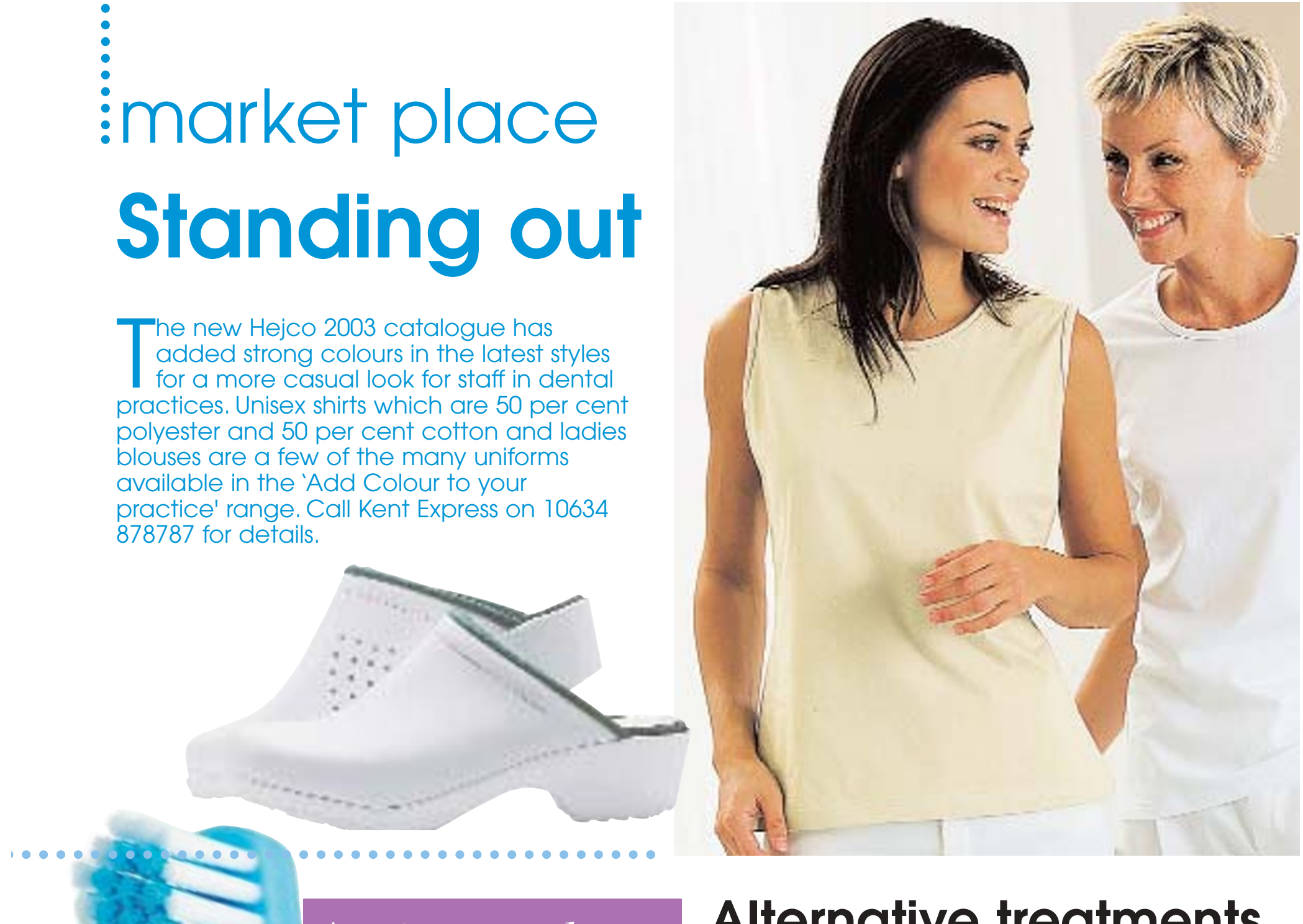

\title{
Alternative treatments
}

In answer to the growing demand for

complimentary products for use within dentistry, the

Dental Directory has introduced a range of

complementary, alternative and nutritional products designed to strengthen the body's own immune and healing system.

The range includes ThioCare Toothpaste, ThioCare Oral Spray and Herbal Mouth and Gum Therapy, which contains echinacea, goldenseal and calendula. For details contact the Dental Directory on 01376391100.

ings), has a replaceable snap-on cap and can be

left clean and dry once used.

Fresh and Go retails at $£ 1.99$ and is available

from DHB, Dental Directory, Orthocare and

Davis Healthcare Services.
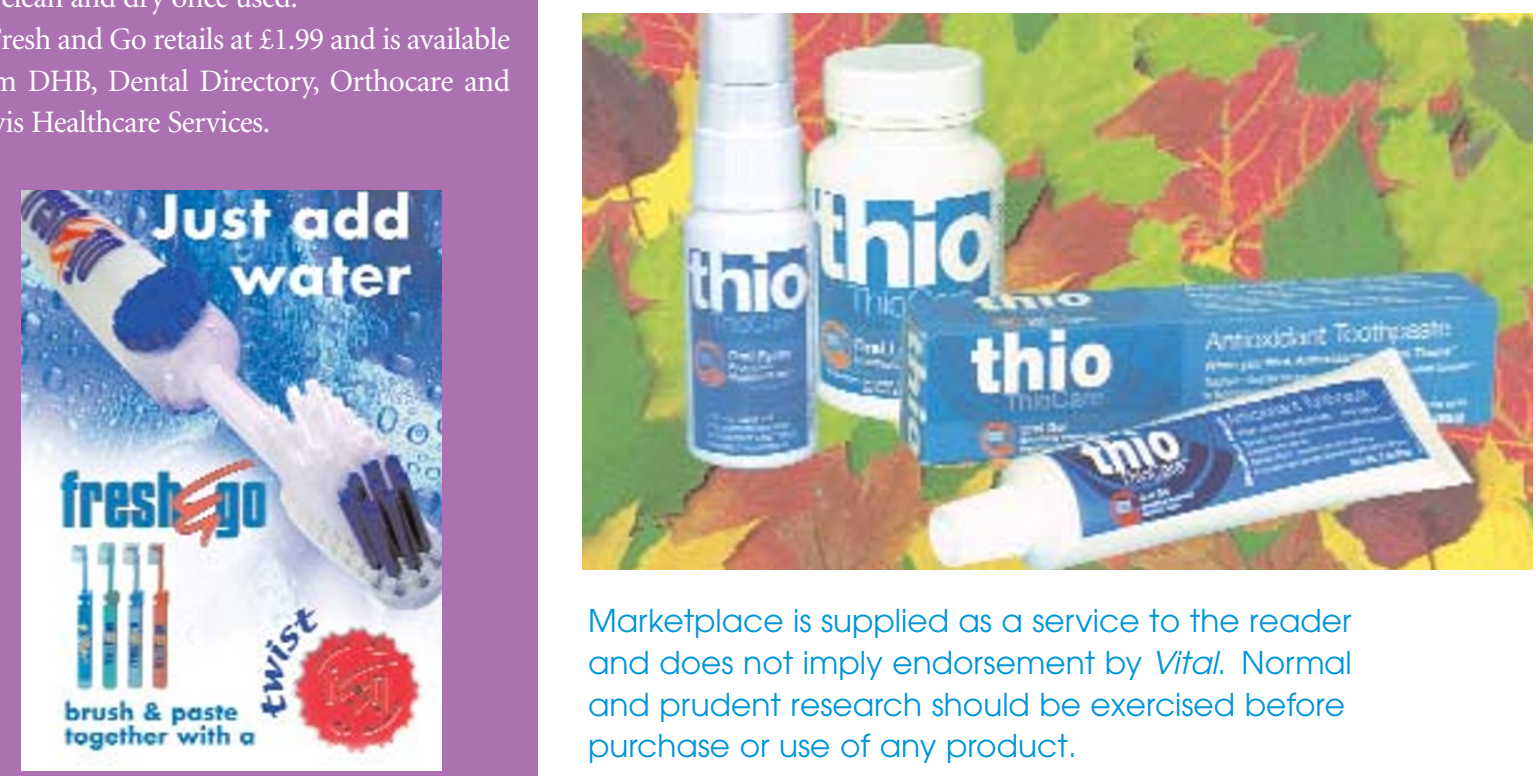

Marketplace is supplied as a service to the reader and does not imply endorsement by Vital. Normal and prudent research should be exercised before purchase or use of any product. 